\title{
Clinical features and laboratory values associated with disease severity in Covid-19 patients: a single center experience
}

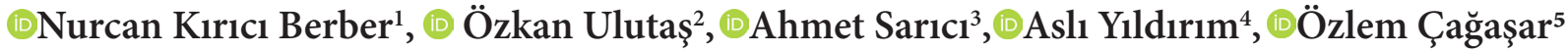 \\ (D) Harika Gözükara Bağ ${ }^{6}$, @illhami Berber ${ }^{3}$ \\ ${ }^{1}$ Malatya Training and Research Hospital, Department of Chest Diseases, Malatya, Turkey \\ ${ }^{2}$ İnönü University Department of Nephrology, Malatya, Turkey \\ ${ }^{3}$ İnönü University Department of Adult Hematology, Malatya, Turkey \\ ${ }^{4}$ Malatya Training and Research Hospital, Department of Medical Oncology, Malatya, Turkey \\ ${ }^{5}$ Malatya Training and Research Hospital, Department of Infectious Diseases, Malatya, Turkey \\ ${ }^{6}$ İnönü University Department of Biostatistics, Malatya, Turkey
}

Cite this article as: Kırıcı Berber N, Ulutaş Ö, Sarıcı A, et al. Clinical features and laboratory values associated with disease severity in Covid-19 patients: a single center experience. J Health Sci Med 2021; 4(1): 18-22.

\begin{abstract}
Background: To date, several studies were published about clinical features and laboratory values associated with disease severity in Covid-19 patients. We aimed to show the relationship between disease severity and clinical and laboratory characteristics of the patients as a single center experience.

Material and Method: Clinical features and laboratory data of fifty patients diagnosed with Covid-19 by PCR was evaluated at diagnosis. These patients divided into 2 groups as early and advanced disease. Clinical features and laboratory data were compared in terms of severity of disease.

Results: In all patients, the most common accompanying disease was coronary artery disease. Cough and headache were the most common complaints. Laboratory values showed low lymphocyte count and high CRP levels in all patients. Twenty four patients in early stage and 26 patients in advanced stage were compared in terms of clinical features and laboratory values. In advanced stage, it was observed that body weight, number of comorbid diseases, age, CRP, procalcitonin, BUN, GGT, fibrinogen, D-dimer and ferritin levels of patients were higher whereas height, serum total protein, albumin and potassium levels were lower when compered with early stage patients $(\mathrm{p}<0.05)$.

Conclusions: Our data showed that older age, having cough, increased number of comorbid diseases, CRP, BUN, GGT, fibrinogen, D-dimer and ferritin and decresed serum total protein, albumin, potassium levels at the time of diagnosis in Covid-19 patients were associated with advanced stage disease.
\end{abstract}

Keywords: Covid-19, disease severity

\section{INTRODUCTION}

Coronaviruses $(\mathrm{CoV})$ are a large family of viruses showing wide clinical variation from common gribal infection to more serious diseases such as the Middle East Respiratory Syndrome (MERS-CoV) and severe Acute Respiratory Syndrome (SARS-CoV). Since December 8, 2019, several cases of pneumonia of unknown etiology have been reported in Wuhan, a city within the Hubei province of China. The disease and the virus that causes it have been named as Covid-19 and SARS-COV-2, respectively and ultimately it was declared as a pandemic disease by WHO on March 11, 2020 (1-3). Most patients eventually made a recovery after careful treatment, but, some developed more severe and even critical illness $(4,5)$. Although early diagnosis and timely treatment of critical cases is very crucial, factors related to disease severity are still unclear.

To date, the severity of the disease has been shown to be related to many clinical futures and laboratory parameters, such as age, presence of co-morbidities, (like diabetes, obesity, heart disease), elevated blood urea nitrogen (BUN), creatinine, procalcitonin, lactate dehydrogenase, D-dimer, C-reactive protein (CRP), neutrophil, lymhocyte counts and pro-inflammatory 
cytokines, such as interleukin-6, respectively (6-8). So, we aimed to show correlation between clinical and laboratory data and the severity of Covid-19 infection in adults as a single center experience.

\section{MATERIAL AND METHOD}

\section{Patients}

The data of Covid-19 patients diagnosed with polymerase chain reaction (PCR), between June 10, 2020 and june 30, 2020 were analyzed retrospectively.

Fifty Covid-19 patients were included in this study. Early and advenced stage patients included to this study were compared in terms of their age, gender, body surface area, symptoms (for instance fever, cough, sputum, sore throat, diarrhea, headache), leukocytes, neutrophils, hemoglobin, hematocrit, lymphocytes, eosinophils, monocytes, platelets, CRP, BUN, creatinine, total protein, albumin, procalcitonin, aspartate aminotransferase (AST), alanine aminotransferase (ALT), alkaline phosphatase (ALP), gamma glutamyl transferase (GGT), sodium, potassium, International Normalized Ratio (INR), activated Partial Thromboplastin Time (aPTT), fibrinogen, D-dimer, ferritin, hospitalization time and mortality rates.

\section{Laboratory Analysis}

Real-time reverse transcriptase-polymerase chain reaction (PCR) tests for SARS-CoV-2 RNA were performed using nasopharyngeal swabs. Total nucleic acid extraction of nasopharyngeal swabs of viral isolates was performed using a biospeedy and coyote extraction system (Bioeksen ltd and Coyote Bioscience ltd). Real-time PCR (RT-PCR) assays for SARS-CoV-2 RNA detection were performed using Biospeedy Covid-19 RT-qPCR Detection Kit (Bioeksen, Istanbul, Turkey).

\section{Disease Severity}

Patients were divided into 4 stage according to their clinical status. Stage 1; asymptomatic (without any symptoms), stage 2; symptomatic without lung involvement, stage 3; symptomatic with lung involvement, stage 4; acute respiratory distress syndrome, intubation, multiorgan failure $(9,10)$. Stage 1,2 patients were accepted as early stage and 3,4 patients were accepted as advanced stage patients.

\section{Statistical Analysis}

Data analysis was performed using IBM SPSS v26 software. Descriptive statistics were used to summarize data. Variables assessed for normal distribution with the Kolmogorov Smirnov test. Categorical data were presented as number-percentages, and numerical data were presented as median, minimum, and maximum.
Differences between categorical variables were analyzed with the Chi-Square test, and numeric variables were compared with the Mann-Whitney U test. A two-sided $p$-value $\leq 0.05$ was considered statistically significant.

The study was approved by the research ethics committee (date/reference number: 30-06-2020/892). All analyses were performed in accordance with the principles of the Declaration of Helsinki.

\section{RESULT}

Fifty patients were included in the study. When the comorbid diseases of the patients were evaluated, most common accompanying disease was coronary artery disease and second was hypertension. Cough and headache were the most common complaints in hospital admissions. Laboratory values showed low lymphocyte count and high CRP levels (Table 1).

Twenty four patients in early stage and 26 patients in advanced stage were compared in terms of clinical features and laboratory values (Table 2). In advanced stage, it was observed that body weight, number of comorbid diseases, age, CRP, procalcitonin, BUN, GGT, fibrinogen, D-dimer and ferritin levels of patients were higher whereas height, serum total protein, albumin and potassium levels were lower when compered with early stage patients $(\mathrm{p}<0.05)$.

\section{DISCUSSION}

In our study clinical and laboratory features evaluated in Covid-19 patients were compatible with the literature. Rodriguez-Morales et al. (6) performed a systematic literature review with meta-analysis, using three databases to assess clinical, laboratory, imaging features, and outcomes of Covid-19 confirmed cases. They showed that fever $(88.7 \%)$, cough $(57.6 \%)$ and dyspnea $(45.6 \%)$ were the most prevalent manifestations. Cough and headache were the most common symptoms in our study. Three patients included in our trial had dyspnea. They reported that the mean age of patients across 18 studies was 51.97 (46.06-57.89), and male sex was 55.9 (51.6-60.1). Patients presented comorbidities were $36.8 \%$ of all cases. Most prevalent comorbid diseases were hypertension (18.6\%), cardiovascular disease (14.4\%), and diabetes (11.9\%). In our study, the median age was 44 years, the ratio of women to men was equal, and the most common comorbid disease was coronary artery disease. Gürbüz P. reported that obesity has been obtained to be an independent and important risk factor for Covid-19 process in nearly all researches (11). Higher BMI but not significantly was evaluated in advanced disease in our study. 
Table 1. Clinical features and laboratory values of all the patients

Characteristics and labratory values (normal range)

All patients median (min-max)

\begin{tabular}{|c|c|c|c|}
\hline \multicolumn{3}{|l|}{ Total number of patients } & 50 \\
\hline \multicolumn{3}{|l|}{ Median age } & $44(18-88)$ \\
\hline \multirow{2}{*}{$\begin{array}{l}\text { Gender } \\
\text { (Number/percent) }\end{array}$} & \multicolumn{2}{|l|}{ Female } & $25(50)$ \\
\hline & \multicolumn{2}{|l|}{ Male } & $25(50)$ \\
\hline \multicolumn{3}{|l|}{ Height (centimeter) } & $162(153-185)$ \\
\hline \multicolumn{3}{|l|}{ Weight (kilogram) } & $70(50-110)$ \\
\hline \multicolumn{3}{|l|}{ Body surface area $\left(/ \mathrm{m}^{2}\right)$} & $1.77(1.47-2.1)$ \\
\hline \multirow{8}{*}{ Number of comorbid disease } & \multicolumn{2}{|c|}{ Hypertension (HT) } & 4 \\
\hline & \multicolumn{2}{|c|}{ Coronary artery disease (CAD) } & 5 \\
\hline & \multicolumn{2}{|c|}{ Diabetes mellitus (DM) } & 1 \\
\hline & \multicolumn{2}{|c|}{$\begin{array}{l}\text { Asthma/chronic obstructive pulmonary } \\
\text { disease (COPD) }\end{array}$} & 2 \\
\hline & \multicolumn{2}{|l|}{$\mathrm{DM}+\mathrm{HT}$} & 2 \\
\hline & \multicolumn{2}{|l|}{$\mathrm{COPD}+\mathrm{HT}$} & 2 \\
\hline & \multicolumn{2}{|l|}{$\mathrm{CAD}+\mathrm{HT}$} & 3 \\
\hline & \multicolumn{2}{|c|}{ Number of all comorbid disease } & 25 \\
\hline \multirow{6}{*}{ Symptoms (number, (\%)) } & \multicolumn{2}{|l|}{ Fever } & $23(46)$ \\
\hline & \multicolumn{2}{|l|}{ Cough } & $34(68)$ \\
\hline & \multicolumn{2}{|l|}{ Sputum } & $11(22)$ \\
\hline & Throat ache & & $7(14)$ \\
\hline & Diarrhea & & $15(30)$ \\
\hline & Headache & & $34(68)$ \\
\hline & Farly & Stage I & $1(2)$ \\
\hline Stage (number (0/)) & Eariy & Stage II & $23(46)$ \\
\hline stage (number, (\%)) & & Stage III & $24(48)$ \\
\hline & Advanced & Stage IV & $2(4)$ \\
\hline & Leukocyte & & $5.19(2.83-20.36)$ \\
\hline & Neutrophil & & $3.27(0.86-18.81)$ \\
\hline & Hemoglobi & $\mathrm{gr} / \mathrm{dL})$ & $13.95(8.5-17.9)$ \\
\hline & Hematocrit & & $40.75(25.6-52.7)$ \\
\hline Complete blood count (median) & Lymphocyt & $\left.10^{3} / \mu \mathrm{L}\right)$ & $1.28(0.39-2.53)$ \\
\hline & Monocyte & $/ \mu \mathrm{L})$ & $0.47(0-1.16)$ \\
\hline & Eosinophil & $\mu \mathrm{L})$ & $0.02(0-0.6)$ \\
\hline & Platelet (15 & & $210(116-389)$ \\
\hline C-reactive protein $(0-0.35 \mathrm{mg} / \mathrm{dL})$ & & & $0.56(0-15.7)$ \\
\hline BUN (5.1-16.8 mg/dL) & & & $31(13-98)$ \\
\hline Creatinine $(0.57-1.25 \mathrm{mg} / \mathrm{dL})$ & & & $0.75(0.43-1.81)$ \\
\hline Total protein $(6.4-8.3 \mathrm{~g} / \mathrm{dL})$ & & & $7(5.62-8.7)$ \\
\hline Albumin (3.5-5 gr/dL) & & & $4.2(2.59-5.04)$ \\
\hline Procalcitonin (0-0.5 ng/mL) & & & $0.05(0.01-3.51)$ \\
\hline AST (5-34 U/L) & & & $27(11-89)$ \\
\hline $\operatorname{ALT}(0-55 \mathrm{U} / \mathrm{L})$ & & & $21(7-93)$ \\
\hline $\operatorname{ALP}(40-150 \mathrm{U} / \mathrm{L})$ & & & $78(11-210)$ \\
\hline GGT (9-64 U/L) & & & $19(8-189)$ \\
\hline Sodyum (136-145 mmol/L) & & & $138(126-142)$ \\
\hline Potasyum (3.5-5.1 mmol/L) & & & $4.1(3.4-5.4)$ \\
\hline INR (0.8-1.2) & & & $1.2(0.92-2.80)$ \\
\hline APTT (23-35 sn) & & & $24.78(18.6-58)$ \\
\hline Fibrinogen (150-350 mg/dL) & & & $295(2.48-743)$ \\
\hline D-dimer $(0-0.55 \mathrm{mg} / \mathrm{L})$ & & & $0.17(0-3.98)$ \\
\hline Ferritin $(22-322 \mathrm{ng} / \mathrm{mL})$ & & & $105.5(7.69-1475)$ \\
\hline Lenght of stay in hospital (day) & & & $5(1-17)$ \\
\hline Mortality (number/percent) & & & $2(4)$ \\
\hline
\end{tabular}




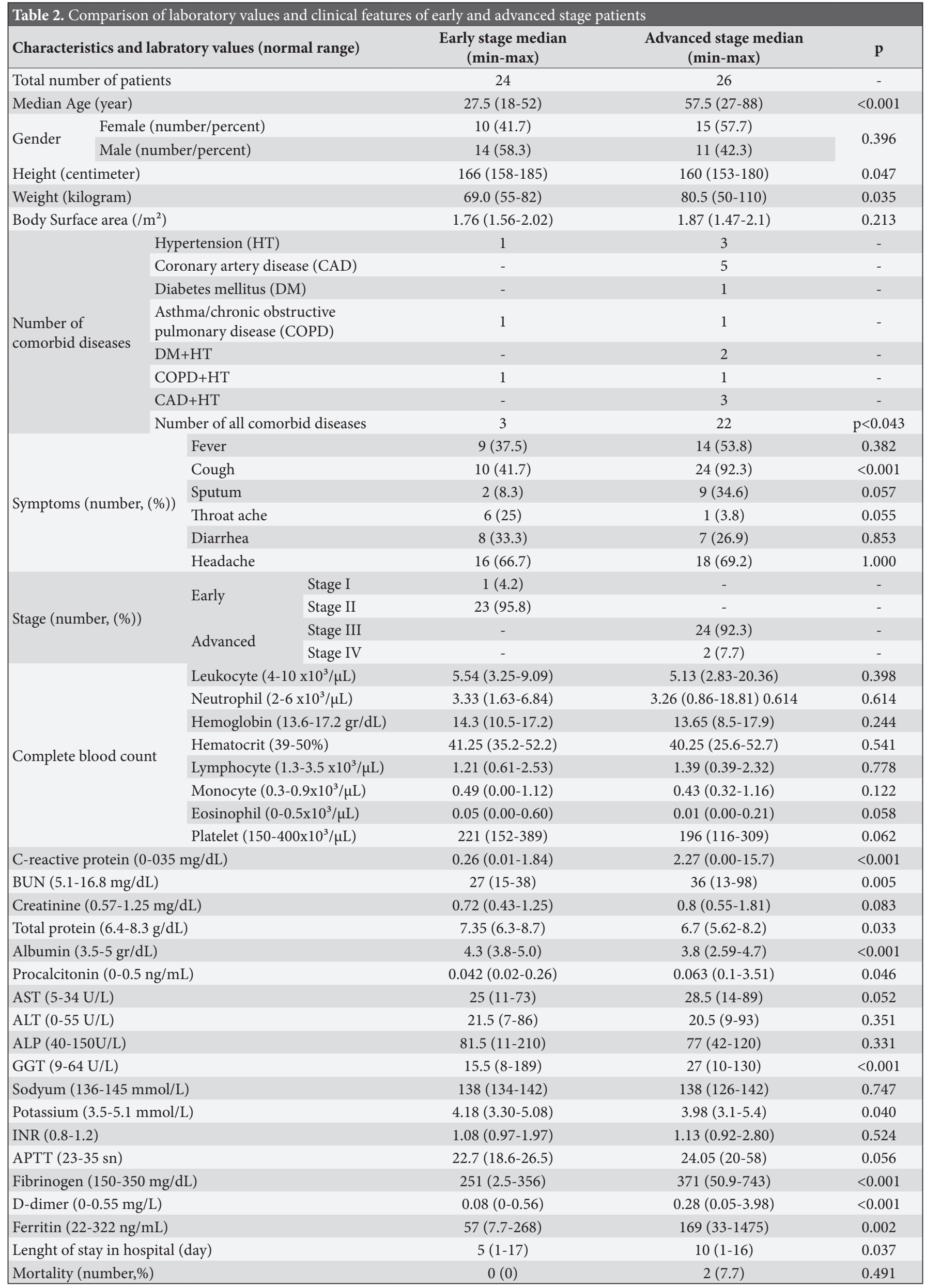


Weiliang Cao et al. (7) compared patients that aged between $21 \sim 50,51 \sim 65$, over 66 years who were accounted for $44.5 \%, 35.1 \%, 18.8 \%$, respectively. Fever $(89.8 \%)$ and cough $(67.2 \%)$ were common clinical symptoms. The rate of patients with sore throats $(14.1 \%)$ was rare. White blood cell counts in the normal range of overall patients, but severe group patients were increased significantly $(\mathrm{p}<0.01)$. Lymphocytes of overall patients were decreased. ALT and AST levels were in the normal range of overall patients, but were elevated in the severe group. Serum creatinine and BUN levels of all patients were in the normal range. CRP level of all patients were increased markedly, which was significantly higher in severe disease group $(\mathrm{p}<0.01)$. In our study, patients in advanced stage were found to be statistically older. The most common symptoms were cough and fever,whereas the least common was chest pain. There was no significant difference in both leukocyte and lymphocyte counts between disease stages. Higher serum GGT and BUN levels were noted especially in advanced stage patients. Creatinine levels were increased, but could not reach to statistically significance. CRP level was increased in all patients. It was significantly increased in advanced stage disease compared to early stage. Gao et al. (8) reported that a comparison of the hematological parameters between the mild and severe groups showed significant differences in interleukin-6 (IL-6), D-dimer, glucose, thrombin time, fibrinogen, and CRP $(\mathrm{p}<0.05)(8)$. We could not eveluate interleukin-6 level in our study. In our study, D-Dimer, fibrinogen and CRP levels were statistically higher in advanced stage disease. Moreover, potassium levels, which was not evaluated in these two studies, was significantly lower disease and the length of hospital stay was longer in advanced stage in our study. Although no mortality was observed in early stage patients, 2 patients died due to infection in advanced stage group. The present study has several limitations. The study was retrospective and had a small sample size. For this reason, we did not associate clinical data with disease prognosis.

\section{CONCLUSION}

Our data showed that older age, having cough, increased number of comorbid diseases, CRP, BUN, GGT, fibrinogen, D-dimer and ferritin and decresed serum total protein, albumin, potassium levels at the time of diagnosis in Covid-19 patients were associated with advanced stage disease.

\section{ETHICAL DECLARATIONS}

Ethics Committee Approval: The study was approved by the research ethics committee (date/reference number: 30-06-2020/892).
Informed Consent: All patients signed the free and informed consent form.

Referee Evaluation Process: Externally peer-reviewed. Conflict of Interest Statement: The authors have no conflicts of interest to declare.

Financial Disclosure: The authors declared that this study has received no financial support.

Author Contributions: All of the authors declare that they have all participated in the design, execution, and analysis of the paper, and that they have approved the final version.

\section{REFERENCES}

1. Li Q, Guan X, Wu P, et al. Early transmission dynamics in Wuhan, China, of novel coronavirus-infected pneumonia. N Engl J Med 2020; 382: 1199-207. doi:10.1056/NEJMoa2001316.

2. Pal M, Berhanu G, Desalegn C, Kandi V. Severe Acute Respiratory Syndrome Coronavirus-2 (SARS-CoV-2): an update. Cureus 2020; 12: e7423. doi:10.7759/cureus.7423.

3. World Health Organization Press Conference. The World Health Organization (WHO) has officially named the disease caused by the novel Coronavirus as Covid-19. Available online: https:// www.who.int/emergencies/diseases/novel-coronavirus-2019 (accessed on 18 May 2020).

4. Chan JF, Yuan S, Kok KH, et al. A familial cluster of pneumonia associated with the 2019 novel coronavirus indicating personto-person transmission: a study of a family cluster. Lancet 2020; 395: 514-23. doi:10.1016/S0140-6736(20)30154-9.

5. Zhu N, Zhang D, Wang W, et al. A Novel Coronavirus from Patients with Pneumonia in China, 2019. N Engl J Med 2020; 382: 727-33. doi:10.1056/NEJMoa2001017.

6. Rodriguez-Morales AJ, Cardona-Ospina JA, Gutiérrez-Ocampo E, et al. Clinical, laboratory and imaging features of Covid-19: A systematic review and meta-analysis. Travel Med Infect Dis 2020; 34: 101623. doi:10.1016/j.tmaid.2020.101623.

7. Weiliang Cao, Li Shi, Lin Chen, Xuemei Xu, Zirong Wu. Clinical features and laboratory inspection of novel coronavirus pneumonia (Covid-19) in Xiangyang, Hubei. medRxiv 2020.02.23.20026963

8. Gao Y, Li T, Han M, et al. Diagnostic utility of clinical laboratory data determinations for patients with the severe Covid-19. J Med Virol 2020; 92: 791-6. doi:10.1002/jmv.25770

9. Lauer SA, Grantz KH, Bi Q, et al. The Incubation Period of Coronavirus Disease 2019 (Covid-19) From Publicly Reported Confirmed Cases: Estimation and Application. Ann Intern Med 2020; 172: 577-82. doi:10.7326/M20-0504

10.Ferguson NM, Laydon D, Nedjati-Gilani G, et al. Impact of non-pharmaceutical interventions (NPIs) to reduce Covid-19 mortality and healthcare demand. Imperial College Covid-19 Response Team 2020; 10: 77482.

11. Gürbüz P. Covid-19 and obesity: a systematic review. İnönü Üniversitesi Sağlık Hizmetleri Meslek Yüksekokulu Derg 2020; 8: 506-14. doi: 10.33715/inonusaglik.735600. 